\title{
Low-Order Webpage Layout in Online Shopping Facilitates Purchase Decisions: Evidence from Event-Related Potentials
}

This article was published in the following Dove Press journal: Psychology Research and Behavior Management

\author{
Qian Shang' \\ Jia Jin (1D ${ }^{2}$ \\ Guanxiong $\mathrm{Pei}^{3}$ \\ Cuicui Wang ${ }^{4}$ \\ Xiaoyi Wang ${ }^{5}$ \\ Junping $\mathrm{Qiu}^{6}$
}

'School of Management, Hangzhou Dianzi University, Hangzhou, People's Republic of China; ${ }^{2}$ Business School, Ningbo University, Ningbo, People's Republic of China; ${ }^{3}$ Zhejiang Lab, Hangzhou, People's Republic of China; ${ }^{4}$ School of

Management, Hefei University of Technology, Hefei, People's Republic of China; ${ }^{5}$ School of Management, Zhejiang University, Hangzhou, People's Republic of China; ${ }^{6}$ Chinese Academy of Science and Education Evaluation, Hangzhou Dianzi University, Hangzhou, People's Republic of China
Correspondence: Xiaoyi Wang School of Management, Zhejiang University, 38\# Zheda Road, Hangzhou 310027, People's Republic of China Tel +8613857106999

Email kevinwxy@zju.edu.cn

Junping Qiu

Chinese Academy of Science and Education Evaluation, Hangzhou Dianzi University, I I58\# Road 2, Hangzhou 310018 , People's Republic of China Email jpqiu@hdu.edu.cn
Introduction: In online shopping, the webpage layout plays an important part in the consumer's experience. The present study aims to investigate whether the webpage order and which order level (high order vs low order) facilitate consumers' instant purchase decisions for products.

Methods: Fourteen right-handed healthy undergraduates and graduate students participated in the experiment as paid participants. In the experiment, participants were presented with daily products in different online shopping webpages (high-order vs low-order) and reported their purchase intentions between purchase and not purchase. Meanwhile, Electroencephalogram (EEG) was recorded from the participants throughout the experiment. In the analysis process, two event-related potentials (ERP) components, P2 and late positive potential (LPP) were mainly focused to examine the cognitive mechanism underlying the purchase decisions.

Results: The behavioral data found that the low-order shopping webpage facilitated participants' purchase intentions compared with the high-order one. Neurophysiologically, increased P2 amplitudes and increased LPP amplitudes were revealed for the low-order webpage compared to the high-order webpage. The P2 indicates the early stage of attention engagement and discordant perception, while the LPP can be taken as a reflection of the late stage of the emotional self-control process.

Conclusion: These results provided evidence that webpage order influenced people's purchase decisions. Low-order webpage design invoked more attention engagement and discordant perception and consumed more self-control resources than the high-order webpage design, which contributed to the higher purchase intentions.

Keywords: online shopping, webpage order, purchase decisions, event-related potentials, P2, LPP

\section{Introduction}

Instant purchase, which is defined as "a sudden, often powerful and persistent urge to buy something immediately", plays a major part in marketing management especially in the context of supermarkets and online shopping sites. ${ }^{1,2}$ Given its importance, a substantial body of research has investigated the influencing factors of intention to purchase. The shopping environment has been identified as a crucial factor influencing consumers' instant buying tendencies and behaviors. For example, Youn and Faber (2000) indicated that instant buying could be significantly influenced by environmental factors such as atmospheric cues in a retail setting, marketer-controlled cues, and marketing mix stimuli. ${ }^{3}$ Parsad et al (2018) demonstrated that the retail shopping 
environment (e.g., display of the goods, crowd inside the store) considerably influenced consumers' instant buying tendency. ${ }^{4}$ This environmental effect on instant buying did not appear only in the physical store. In fact, the online shopping environment, which transcends time and space plays a more important role in instant buying. For example, Adelaar et al (2003) proposed a theoretical model that demonstrated that the online shopping environment could trigger consumers' emotional responses and then predict consumers' behavioral responses to instant buying. ${ }^{5}$ Akram et al (2018) showed that website quality in an online shopping environment positively affected consumers' instant purchase behavior. $^{6}$

In the online shopping environment, two main dimensions - webpage order and webpage complexity — are strong determinants of users' perceptions and satisfaction. ${ }^{7-10}$ The webpage's order is related to the logical organization, coherence, and clarity of the webpage's content and layout. ${ }^{8,9,11}$ Generally, people believe that an orderly arranged environment can promote a positive emotional perception. ${ }^{12}$ Meanwhile, consumers' emotional responses are positively related to their purchase intentions. ${ }^{5,13}$ Thus, it is hypothesized that the higher the order of the online shopping site's layout is, the greater the purchase rates.

However, other researchers have shown that a visually disorder or uncertain environment might yield negative emotional perceptions (e.g. threatening sense) and diminish the user experience. ${ }^{14,15}$ When people attempt to modulate a negative emotion or suppress an emotional expression, many self-control resources are occupied, leading to reductions in self-control capacity. ${ }^{16-18}$ Self-control resources are general (cognition control, emotion regulation, etc.) but finite. ${ }^{16,19}$ Self-control capacity is defined as one's ability to manipulate one's emotions and behaviors using self-control resources. ${ }^{2,20}$ Many researchers have found that a decrease in self-control resources and capacity tends to be accompanied by instant buying. ${ }^{16,19,21,22}$ Fenton-O'Creevy et al (2018) suggested that people's instant buying could be understood as a failure of self-control in relation to long-term goals and as a strategy for emotional regulation. ${ }^{21}$ Efendi et al (2019) also showed that consumers' self-control had a negative and significant influence on their purchase decisions, and good self-control would reduce consumptive behavior. ${ }^{22}$ Based on this perspective, a low-order webpage layout might also trigger buying tendencies that would facilitate purchase decisions.

Whether a high- or low-order layout of an online shopping webpage evokes higher purchase rates remains controversial. Therefore, to solve this issue, this study explores the underlying cognitive mechanism by which webpage layout design affects consumers' purchase decisions. We adopt the measurement of event-related potentials (ERP), a noninvasive neuroscience technology that can directly detect people's brain cognitive activity underlying their behaviors. ${ }^{23}$ ERP is the electrophysiological activity from the brain scalp in response to stimulus, reflecting the summed activation of excitatory postsynaptic potential and inhibitory postsynaptic potential elicited by a stimulus. ${ }^{24,25}$ Meanwhile, ERP has an excellent temporal resolution in milliseconds that it can record the cognitive activity during behavior and decision-making process in real time, which cannot be obtained by traditional consumer research methods. ${ }^{26}$ Thus, in our study, examining subjects' brain activity while they perform purchase tasks under different webpage order stimuli can help deeply understand how people evaluate webpage order stimuli and make purchase decisions during the cognition process. Based on prior researches on stimulus evaluation and decision-making, two important components (P2 and Late positive potential (LPP)) were focused on in the present study.

\section{Literature Review}

$\mathrm{P} 2$, an ERP component, is a positive potential that peaks approximately $200 \mathrm{~ms}$ after stimulus presentation. ${ }^{27,28}$ Numerous studies indicate that the $\mathrm{P} 2$ reflects the rapid automatic activity of attention capture. ${ }^{27,29-31}$ For example, Carretié et al (2001) found that P2, which is related to attention engagement, demonstrated larger amplitudes in response to negative stimuli than in response to positive stimuli. $^{29}$ Upon exposure to warning signal words, P2 reflects the attentional negativity bias to detect the hazard of warning signal words. ${ }^{27}$ Wang et al (2019) showed that negative emotion-label words (e.g., angry) and negative emotion-laden words (e.g., selfish) could elicit larger P2 components than did neutral words (e.g., natural) in a lexical decision task. ${ }^{31}$ In these studies, the enhanced P2 amplitude suggested an attentional bias to emotionally negative stimuli.

Moreover, recent evidence has shown that P2 is related to the cognitive activity of incongruent judgment. ${ }^{32-35}$ For example, when presenting subjects with a target that was either congruent or incongruent with the semantic category of items, Freunberger et al (2007) found that P2 demonstrated top-down semantic regulation with larger amplitudes for incongruent targets compared with congruent 
ones. ${ }^{32}$ In the research of Zioga et al (2019), a larger P2 component was response to incorrect notes than correct notes, which reflected the information processing of incorrect associated with learning. ${ }^{33}$ A semantic deductive experiment by Lei et al (2010) showed a greater P2 for the atypical members of target semantic categories than the typical members, which was involved in the early detection of category classification. ${ }^{34}$ Ma et al (2014), using a prime-probe paradigm to investigate brand extensions, demonstrated that P2 was sensitive to early lowlevel and similarity-based evaluation. ${ }^{35}$ In the current study, we hypothesized that a low-order webpage was more likely to induce negative emotions and appear atypical, which might attract more attentional resources and incongruent judgment demands compared to a high-order webpage, as reflected by a larger P2 amplitude.

In addition to P2, LPP reflects the later stage of the stimulus evaluation. LPP mainly reaches its maximum amplitude between 300 and $800 \mathrm{~ms}$ after stimulus presentation. ${ }^{36,37}$ A line of evidence has shown that LPP is sensitive to the cognitive process of emotion regulation. ${ }^{38-42}$ In an experiment by Huang and Luo (2006), ${ }^{38}$ negative pictures were found to elicit a higher LPP component compared to positive and neutral pictures, thus suggesting a negative bias of cognitive regulation resources in the later evaluation activity. Dennis and Hajcak (2009) showed that LPP was larger in the condition of unpleasant picture-negative interpretation than in the condition of unpleasant picture-neutral interpretation, suggesting that LPP represents a neural marker for emotional regulation and mood disruption. ${ }^{39}$ When subjects were required to increase versus decrease their emotional response to an unpleasant picture, a larger LPP magnitude was observed, thus reflecting a self-regulation process of emotional stimuli. ${ }^{40}$ In an affective-cueing experiment consisting of cues (red squares and blue circles) signaling the likely valence of following target images (negative or neutral), Brudner et al (2018) revealed increased LPP responses to negative than neutral cues and cued targets. ${ }^{41}$ Moreover, Dunning and Hajcak (2009) implied that LPP was a useful tool in identifying similarities and differences across emotional regulation strategies. ${ }^{42}$ Thus, given the functional sensitivity of LPP, we proposed that LPP represented an emotional regulation process for the stimulus materials in the later evaluation stage. We predicted that the LPP amplitude might be larger for the low-order webpage than for the high-order one, suggesting a higher occupation of emotion-regulation resources.

In the current study, we used ERP to explore the underlying cognitive mechanism of how webpage order in online shopping affects consumers' purchase decisions. The participants were presented with daily products in a webpage environment with different order levels and instructed to evaluate their purchase decisions. We tested the following two presumptions: (1) a low-order webpage increases people's purchase decision, and (2) this underlying cognitive mechanism of a low-order webpage is reflected in two stages: P2 (occupying more attention resources and discordant perception) and LPP (emotional self-control resource allocation).

\section{Methods}

\section{Participants}

A total of fourteen right-handed, 19- to 23-year-old healthy undergraduates and graduate students (8 females) from university voluntarily participated in our experiment as paid participants (see Table 1). One participant's data were excluded because of many invalid trials. All participants were native Chinese speakers, had normal or corrected-tonormal vision, and did not report a history of having a neurological disorder or mental disease. All participants signed informed consent to participate in the study. Experiments were conducted according to the guidelines of the institutional ethics committee of the Zhejiang University Neuromanagement Lab, which approved all experimental protocols.

\section{Experimental Stimuli}

A total of 35 daily products worth approximately $¥ 30$ (approximately \$5) selected from the famous Taobao Marketplace (http://www.taobao.com/) were adopted in our experiment. These products were separately placed into two groups of online shopping webpages as the target stimuli. One group was the high-order webpage layout (the contextual information in the online shopping site was arranged in an orderly layout like that normally used in online shopping; i.e., all labels and buttons were arranged in an orderly manner in a two-end alignment format, while the other group was the low-order one (the online shopping site was designed in a low-order layout; i.e., most of the labels and buttons were staggered and were neither horizontally nor

Table I Description of Experimental Participants

\begin{tabular}{|c|c|c|c|c|}
\hline $\begin{array}{l}\text { Participants } \\
\text { Sex }\end{array}$ & Number & $\begin{array}{l}\text { Age } \\
\text { Range } \\
\text { (Year) }\end{array}$ & \multicolumn{2}{|c|}{ 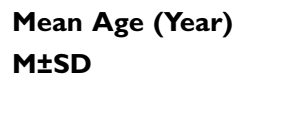 } \\
\hline Female & 8 & $19-23$ & $21.25 \pm 1.30$ & $21.28 \pm 1.39$ \\
\hline Male & 6 & $19-23$ & $21.33 \pm 1.49$ & \\
\hline
\end{tabular}


vertically aligned. All stimuli were displayed as visual pictures on a 19-inch computer monitor $(1280 \times 1024$ pixels $)$, and the size of each picture was $300 \times 400$ pixels.

Before the formal experiment, we performed a pretest with 7-point items to evaluate the order level (1, very disordered, and 7, very orderly) of the stimuli and collected 91 valid data (see Appendix 1). Statistical analysis using the $t$-test revealed a main effect of order level between the high-order group $(M=5.52, S E=0.02)$ and the low-order group $(M=2.99 S E=0.01)\left[t_{(90)}=100.84, p=0.00\right.$ $(\mathrm{p}<0.01)]$ (see Appendix 2).

\section{Experimental Procedure}

The entire experiment included 70 trials, which were divided into two blocks. The participants were seated $90 \mathrm{~cm}$ from a controlled computer that was used to display the experimental stimuli. The stimuli were presented using the Stim2 system (Neurosoft Labs, Inc., Sterling, VA, USA). During the presentation, purchase intention was required to report by using a keypad (press button " 1 " or "3" to purchase or not purchase). The response-to-hand assignments were counterbalanced across individuals; i.e., half of the participants were required to press " 1 " for "purchase" and "3" for "not purchase", while the opposite pattern was used for the other half of the participants.

Before the experiment, the participants were told that they were going to be taking part in an online shopping experience and that they had no preplanned products to buy. Each trial (see Figure 1) started with a fixation cross $(500 \mathrm{~ms})$ in the center of the screen, which was followed by a target stimulus. The target stimulus could be either a highorder condition or a low-order condition and appeared for
$1000 \mathrm{~ms}$. To prevent the subjects from predicting the type of upcoming stimulus, all stimuli appeared randomly. For each target stimulus, the participant was instructed to make a decision on whether they would buy the product. They had a maximum of $2000 \mathrm{~ms}$ (including the time of target presentation and interval between trials) to give their response by pressing a button. The sequential stimuli were separated by blank screens that lasted for 400-600 ms. We balanced the assignment of the response hand across participants to eliminate the interference of this parameter. The formal experiment began after 10 separate test trials, which were provided to allow the participants to practice and become familiar with the experimental procedure.

\section{EEG Recordings and Analyses}

EEG was recorded continuously using a set of $64 \mathrm{Ag} / \mathrm{AgCl}$ electrodes according to the 10-20 system. The EEGs were sampled at $500 \mathrm{~Hz}$ with a $0.05-100-\mathrm{Hz}$ bandpass using a Neuroscan Synamp2 Amplifier (Scan 4.3.1, Neurosoft Labs, Inc. Virginia, USA). The left mastoid was used as the reference during recording, and later the average of the two mastoids was calculated as the off-line reference. To monitor the electrooculograms (EOGs), two pairs of electrodes were separately placed above and below the left eye and the external canthi of both eyes. The electrode impedances were kept below $5 \mathrm{k} \Omega$.

During off-line processing, the EEG recordings were segmented for the epoch between -200 and $800 \mathrm{~ms}$ of stimulus onset. Baseline correction was conducted using the pre-stimulus of $200 \mathrm{~ms}$ as the baseline (i.e., subtracting the voltage measured during the pre-stimulus window). Ocular artifacts (such as eye blinks, eye movements)
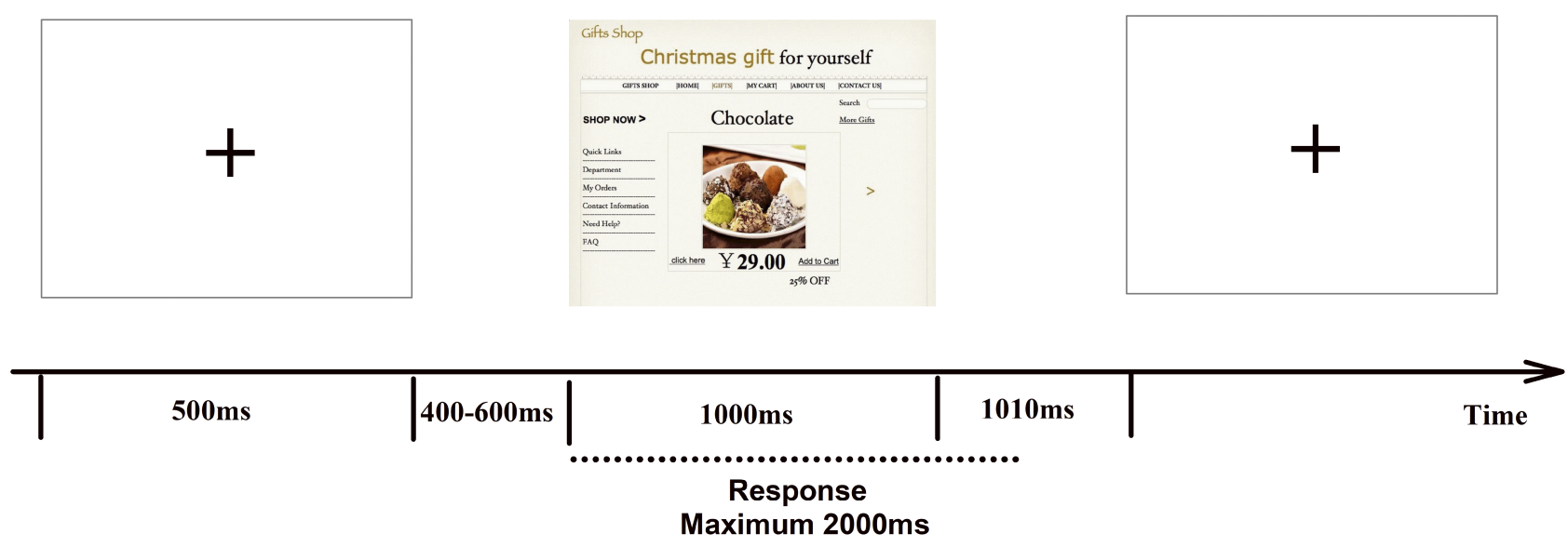

Figure I Experimental procedure. The subjects were presented with two types of webpage order [high order and low order]. They were instructed to report their purchase intentions. During the experiment, EEGs were simultaneously recorded. 
were excluded from the NeuroScan software's regressionbased algorithm. Other artifacts (such as amplifier clipping, bursts of electromyographic activity or peak-to-peak deflections exceeding $80 \mu \mathrm{V}$ ) were excluded from averaging. The ERP was digitally filtered with a low-pass filter at $30 \mathrm{~Hz}(24 \mathrm{~dB} /$ Octave). The data were averaged separately in both conditions (high order and low order).

According to previous ERP studies ${ }^{32,34,41,43}$ and the topographic map, we chose 14 representative electrodes (CP3, CPZ, CP4, P3, PZ, P4, PO7, PO3, POZ, PO4, PO8, $\mathrm{O} 1, \mathrm{OZ}$ and $\mathrm{O} 2)$ in the statistical analysis of $\mathrm{P} 2$ and 6 representative electrodes $(\mathrm{C} 3, \mathrm{CZ}, \mathrm{C} 4, \mathrm{CP} 3, \mathrm{CPZ}$ and CP4) to analyze LPP. Time windows of $150-250 \mathrm{~ms}$ and 580-800 ms were selected to average P2 and LPP, respectively. ANOVA was performed with two factors: webpage order (high order vs low order) and the electrodes. The Greenhouse-Geisser correction and Bonferroni correction were applied when necessary. The effect sizes were measured by both partial eta squared $\left(\eta^{2}\right)$ and Hedges' g. Previous studies indicated that the effect size measured via $\eta^{2}$ of $0.01,0.06$, and 0.14 reflected small, medium, and large effects, respectively. ${ }^{44,45}$ For studies in social psychology, Hedges' gs of $0.15,0.40$, and 0.70 were recommended as small, medium, and large effects, respectively. ${ }^{46,47}$

\section{Results}

\section{Behavioral results}

In the present study, we conducted statistical analyses of participants' purchase rates (PR) and reaction times. PR is defined as the ratio of purchase trials to total decision trials, and the reaction time indicates the time interval between stimuli presentation and the purchase response. PRs for different levels of webpage order (high order vs low order) were analyzed with a paired $t$-test. PR showed a main effect of webpage order $\left[t_{(12)}=-2.27, p=0.043\right]$. The PR was larger in the low-order condition $(M=0.33$, $S E=0.05)$ than in the high-order $(M=0.31, S E=0.05)$. For the response time, the paired- $t$ test found no significant difference between the high-order condition $(M=703.28$ $\mathrm{ms}, S E=44.56)$ and the low-order conditions $(M=702.58$ $\mathrm{ms}, S E=40.62)\left[t_{(12)}=0.07, p=0.943\right]$. (see Appendix 2).

\section{ERP Results}

\section{P2 Amplitude}

The total average ERP for the two order levels of webpage layout (high order vs low order) are shown in Figure 2. The within-subject ANOVAs of P2 amplitude with two factors (webpage order and electrode) revealed a main effect of webpage order $\left[F_{(1,12)}=13.22, p=0.003(p<0.01)\right.$, partial
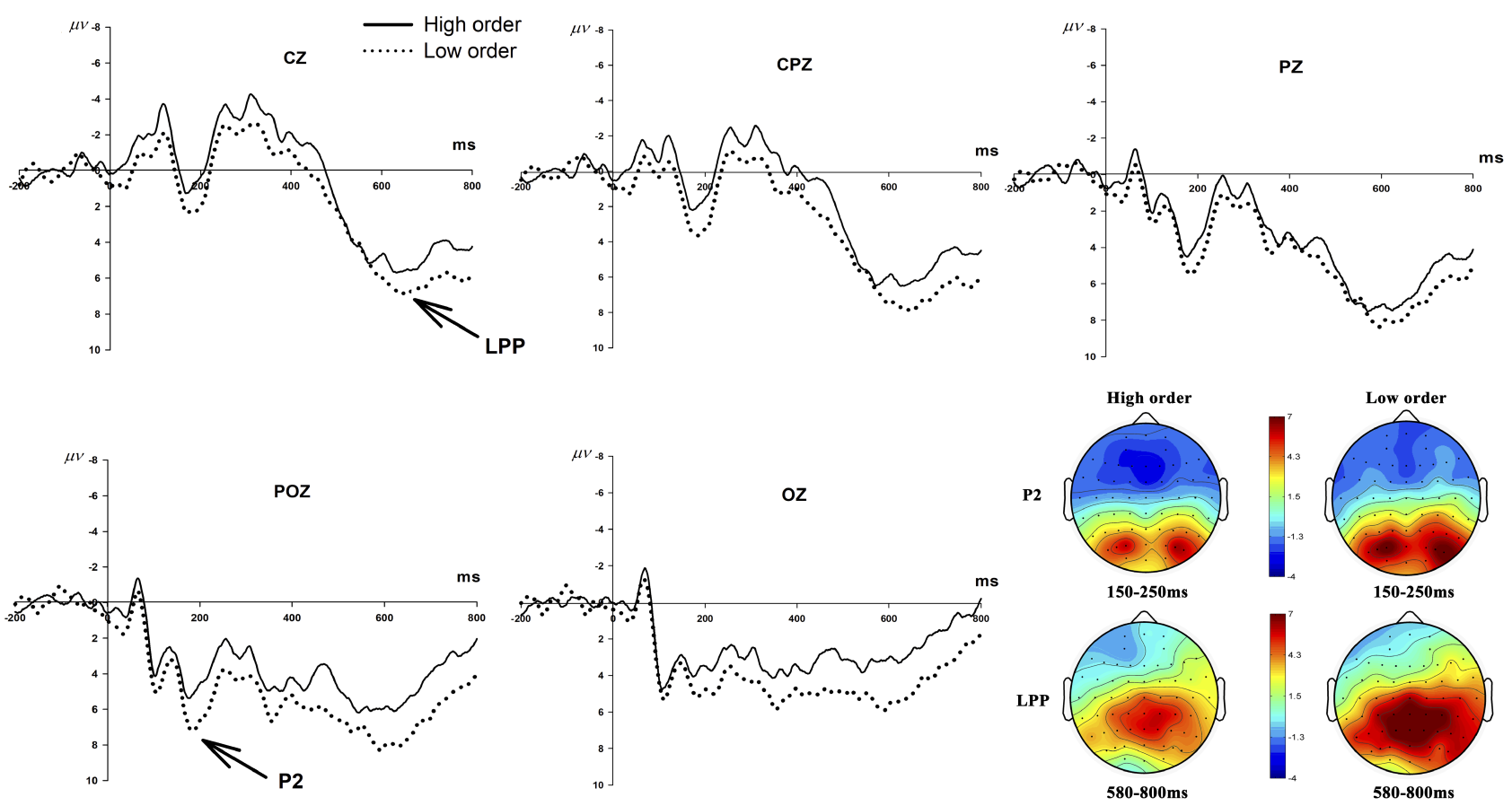

Figure 2 ERP data. Total averaged P2 and LPP evoked by the two webpage orders [high order and low order] from typical electrodes [CZ, CPZ, PZ, POZ and OZ]. The scalp topographic distributions of the P2 and LPP were provided. 
eta squared $\left.\left(\eta^{2}\right)=0.52\right]$ and of electrode $\left[F_{(13,156)}=5.90\right.$, $p=0.000(p<0.01), \eta^{2}=0.33$ ], which showed a large effect size of $\eta^{2}$. The low-order condition $(M=4.92 \mu \nu, S E=0.66)$ showed a higher $\mathrm{P} 2$ amplitude than the high-order condition $(M=3.62 \mu \nu, S E=0.73)$, Hedge's g effect size $=0.51$, which showed a medium effect size of Hedge's g. Webpage order was found to have no interaction effect with the electrode $\left.F_{(13,156)}=1.07, p=0.387, \eta^{2}=0.08\right]$. (see Appendix 2).

\section{LPP Amplitude}

The statistical results for the LPP amplitude for the two factors (webpage order and electrode) exhibited a significant main effect for webpage order $\left[F_{(1,12)}=5.37\right.$, $p=0.039, \eta^{2}=0.31$, large effect size of $\left.\eta^{2}\right]$, indicating that LPP amplitude was higher for the low-order webpage $(M=6.03, S E=0.86)$ than the high-order one $(M=4.40$, $S E=1.08$ ) [Hedge's g effect size $=0.46$, medium effect size of Hedge's g]. The main effect of electrode was significant $\left[F_{(5,60)}=8.98, p=0.000(p<0.01), \eta^{2}=0.43\right.$, large effect size of $\eta^{2}$ ]. The interaction effect between webpage order and electrode was not significant $\left[F_{(5,60)}\right.$ $\left.=0.43, p=0.825, \eta^{2}=0.04\right]$. (see Appendix 2).

\section{Discussion}

By applying ERP, this study aimed to examine how a consumer's purchase decision was affected by the order of the webpage's layout in online shopping. The behavioral and the ERP results showed that the low-order layout could promote consumers' instant purchase during the decision-making process. Regarding the participants' behaviors, higher purchase intents were found for the loworder webpage compared to the high-order one. Moreover, the ERP results indicated that the P2 and LPP components were larger for the low-order webpage than for the highorder condition, thereby providing a cognitive mechanism for the facilitation effect of the low-order webpage on an instant purchase.

\section{Behavioral and Cognitive Mechanism}

The present study discovered a PR effect on the online shopping webpage order. In the low-order condition of the online shopping webpage, the participants showed a higher purchase rate than in the high-order condition. This finding might be attributed to the negative emotional perception and self-control mechanism. As described in the Introduction, a low-order environment might arouse negative emotional perceptions and worse user experiences. ${ }^{14,15}$ In the current study, when the products were presented in a low-order online shopping webpage, people tended to have negative emotional perceptions and tried to use extensive self-control resources to regulate these emotions. Self-control resources are general resources (emotion regulation, cognition control, etc.) that people can employ to manage various situations, such as emotions, incongruencies or behaviors. ${ }^{19}$ However, self-control resources are finite. If one process consumes a large amount of self-control resources from the general resources pool, people are less able to engage in the further process of self-control. ${ }^{16} \mathrm{~A}$ substantial body of empirical researches supports this self-control theory. For example, Vohs \& Heatherton (2000) demonstrated that when dieters expended too much self-control resources to resist the temptation of candy compared to the condition of no temptation, they showed less self-control ability to persist in a difficult puzzle task. ${ }^{48}$ In a dual-task experiment, when participants were required to control their attention away from a series of words appearing on a computer screen, they were found to be more likely to engage in impulsive buying than participants in the condition of no attention-control. ${ }^{19}$ These findings indicated that a temporary reduction in selfcontrol resources and capacity can result in impulsive purchases. ${ }^{16,19,21,22}$ Thus, consistent with these studies, our experiment suggests that a low-order online shopping webpage occupies much more self-control resources to regulate emotions, leading to higher instant purchase relative to the high-order condition. However, there are also some differences between this study and previous experimental researches. ${ }^{16,19}$ In those studies, participants were generally required to complete an explicit task that consumes selfcontrol resources, and then evaluate their purchasing decisions. For example, in experiment 3 of Vohs and Faber (2007), the participants were told that they should smile and convey happiness and enthusiasm using amplified facial expressions and multiple hand gestures in a reading task, which was used to consume participants' self-control resources before performing a purchasing decision task. ${ }^{16}$ In contrast, in our experiment, the participants only needed to complete the purchase decision task in different environments of webpage order, therefore, the information processing of webpage order that consumed self-control resources was implicit rather than explicit. Thus, in addition to explicit tasks, our research found that implicit information processing can also consume self-control resources and promote purchase decisions.

In the cognitive process, the P2 component represents the early activity of attention capturing and incongruent judgment. ${ }^{27,29-32,34,35,49}$ As elaborated in the Introduction, 
negative emotional stimuli (e.g., threat words, warning signal words, and negative pictures) seem to have the priority to attract more attentional resources, which could be reflected by the enhanced P2 amplitude. ${ }^{27,29}$ For instance, Carretié et al (2001) demonstrated that negative stimuli could induce a larger P2 amplitude compared to positive stimuli, which reflected increased attention engagement for negative stimuli. ${ }^{29}$ Ma et al (2010) showed that high hazard of warning signal words attracted more attentional resources. ${ }^{27}$ The attentional priority toward emotionally negative stimuli might be attributed to evolutionary theory, which indicates that people usually give priority to detecting negative stimuli for survival and selfprotection. ${ }^{50-52}$ In this study, the ERP results found larger P2 amplitudes for the low-order online shopping webpage compared with the high-order one. The low-order webpage might induce a negative emotion perception and, consequently, increase attention engagement. Our findings suggested that even if the low-order webpage stimuli only implicitly evoke negative emotions, it could also lead to the negativity bias and increased attention-resource allocation at the early processing stage. It was supported by a recent study of Wang et al (2019), which showed that both negative emotion-laden words (implicitly express emotion, e.g., selfish) and negative emotion-label words (explicitly express emotion, e.g., angry) could elicit larger P2 components than did neutral words (e.g., natural) in a lexical decision task, reflecting attentional resource allocation. $^{31}$ Moreover, previous studies have indicated that $\mathrm{P} 2$ is also involved in incongruent and atypical processing. ${ }^{32,34,35}$ Compared with a high-order online shopping webpage, processing the low-order layout must require a higher visual information integration demand. It is also supported by the previous study of Zioga et al (2019), in which P2 was linked to the neural activity of learning that involves much information processing resources. ${ }^{33}$ Thus, in this study, we suggest that the P2 revealed the early stage of attention engagement and integration processing of discordant information in the cognitive process of online instant purchase.

Following P2, a late LPP component was discovered in the current experiment. Previous studies have indicated that the LPP component can be considered a neural marker for the emotional regulation process in the later evaluation stage. ${ }^{38-40,42}$ The present study showed that when people are presented with a product in a low-order online shopping webpage, they might perceive a negative emotion and try to recruit more cognitive resources to evaluate and regulate these emotions. Emotional management plays an important role in survival and daily life. ${ }^{38}$ Making rational decisions to achieve a specific goal requires people to call upon self-control capacity to manage emotions. ${ }^{18,19}$ In our experiment, in addition to the early automatic process of attention engagement and discordant perception (reflected by P2), a deeper and controlled process was also involved in negative emotion management. This process was reflected by the LPP component, with a larger LPP amplitude in the low-order condition relative to the high-order condition. In this stage, when people perceived negative emotions in the low-order online shopping webpage, they tended to invoke much more evaluation and control resources to manage these emotions because of their importance for survival. These findings are consistent with previous studies that have found that LPP is greater in response to negative stimuli than positive and neutral ones, thereby indicating a negative bias of emotionregulation resources in the later evaluation stage. ${ }^{38-41}$ For instance, in an affective-cueing experiment by Brudner et al (2018), it revealed greater LPP responses to negative versus neutral cues and negatively cued versus neutrally cued target images, which reflected the emotional processing. ${ }^{41}$ However, there are also some differences between the present study and these previous studies. In the previous studies mentioned above, ${ }^{38-41}$ emotional pictures were generally used directly as stimuli that induced LPP components. In contrast, the stimuli in the current study were not explicitly emotional pictures but implicitly emotional stimuli of a webpage order environment that evoked emotions, which could also significantly induce LPP components for emotional processing. Therefore, in this study, we suggested that LPP involves the process of emotional evaluation and regulation and reflects an allocation bias of self-control resources toward different webpage orders in online shopping.

\section{Theoretical and Practical Implication}

The present study provides a new perspective on the impact of environment order in online shopping on an instant purchase. First, many people usually believed that a high-order designed environment in online shopping was more beneficial to consumers' buying experience. This belief was attributed to a positive emotional infection mechanism. ${ }^{5}$ That is, when products are placed in a highorder environment, they can elicit consumers' positive emotional perceptions ${ }^{12}$ and thus promote their buying intent or behavior. ${ }^{5,13}$ However, a shortcoming of these 
studies was that no research was carried out on the direct impact of webpage order factor on consumers' purchasing decisions. One part of previous researches explored the impact of webpage order on consumers' emotional experience, and the other part of researches showed that consumers' emotional experience could influence their purchase decisions. These studies could only provide indirect rather than direct evidence of the impact of webpage order on purchasing decisions. In contrast, the current study carried out an experimental research to explore the direct impact of the webpage order on consumers' purchasing decisions, which made up for the deficiency of previous researches. Moreover, in the present study, we demonstrated a totally different phenomenon in which the low-order shopping webpage showed an advantage over the high-order one in promoting consumers' instant purchase intent. We supposed that this effect was due to a negative emotion regulation mechanism. In the loworder shopping environment, consumers tended to perceive a negative emotion, consistent with the previous findings that a visually uncertain or disorder environment might cause negative emotional perceptions and diminish the user experience. ${ }^{14,15}$ For instance, Wu et al (2016) showed that the disorder of user interface significantly increased user's cognitive load and decreased their experience and satisfaction. ${ }^{14}$ Based on the importance of survival value, more self-control resources were occupied to regulate or suppress the negative emotional expression. However, this decrease in self-control resources resulted in consumers' instant purchase. Our findings are supported by previous research, indicating that people's self-control resources and capacities are limited and that depleting selfcontrol via one response results in less self-control for another. $^{17,18,20}$ Gailliot et al (2007) found that selfcontrol resource could be reflected by blood glucose level, and the low level of blood glucose after an initial self-control task predicted poor control of subsequent thought and behavior. ${ }^{20}$ Regarding the purchase decisionmaking process, a temporary reduction in self-control resources could also lead people to purchase more impulsively. ${ }^{19,21,22}$ In the experiments of Vhos and Faber (2003, 2007), it demonstrated that participants were more likely to be impulsive buyers, buying more items and spending more money when they were required to control their thought or behavior in an initial task. ${ }^{16,19}$ In contrast, good self-control would help reduce consumers' purchase intention that it could be used as a strategy to manage consumers' consumptive behaviors. ${ }^{2,22}$ Second, we found the underlying cognitive mechanism of the purchase decision process using ERP method, which has not been studied in previous researches. In this study, ERP method revealed deep sources of consumers' behavior in the brain, which could not be obtained by traditional selfreporting methods. The participants' purchase decision was affected by the order factor in two stages: P2 and LPP. We found larger P2 and LPP amplitudes for the loworder webpage than for the high-order one. The P2 component reflects the early stage of attention engagement processing and discordant perception, and the LPP component reflects the late stage of self-control resource allocation. These neural indexes provided preliminary cognitive evidence for the facilitation effect of a loworder webpage on instant purchase.

This study also has practical implications for marketing. First, designing an effective webpage layout to promote consumers' purchase decisions is an important issue for online shopping. This study found that the low-order online shopping webpage designing compared to the highorder online shopping webpage designing promoted consumers' purchase rate during the decision-making process. We suggest that online marketers should pay more attention to the factor of webpage layout order and can use appropriate low-order webpage layout to facilitate consumers' purchase behavior. Second, using neuroscientific methods in the current study, we found that low-order webpage design invoked more attention engagement and discordant perception, and consumed more self-control resources than the high-order webpage design, which contributed to the higher purchase intentions. Therefore, we suggest that online marketers should focus on more factors that can attract attention, discordant perception and occupy self-regulating resources when designing the webpage.

\section{Limitations and Future Directions}

Our study has some limitations that need to be improved in future research. First, the current study mainly examined the effect of webpage layout order on people's purchase decisions. There are also some other factors of the webpage (e.g. brand, musical situation) that have important impact on consumers' experience and behavior. For example, researchers found that website brand equity had an influence on consumers' online experience and online loyalty. ${ }^{53}$ Interactive music in the design of an e-commerce website could create a more engaging consumer experience and influence consumer's behavioral intention. ${ }^{54}$ These factors need to be further researched 
in the future studies. Second, the ERP experiment has the inherent limitations of experimental design, which may not perfectly simulate the real online shopping situation. Future study can consider more measurements to improve it. For example, we can carry out field experiments with portable EEG equipment to record people's brain activities in more real situations outside the laboratory. ${ }^{55}$ Third, the effect size was not large enough in the current study which may be due to the fact that the sample size of electrophysiological studies in general is relatively small. A larger sample size should be considered in future studies to further increase the effect size.

\section{Conclusion}

In conclusion, this study investigated how instant purchase by consumers occurs when consumers are presented with online shopping webpages with different levels of layout order. ERP was used to examine the cognitive process underlying the purchase decision for products in the low-order online shopping webpage designing. We found that the low-order shopping webpage facilitated participants' purchase decision, with a higher purchase rate compared with the high-order webpage. At the neural level, it revealed larger P2 and LPP components for the low-order webpage than the high-order webpage. We suggest that a low-order webpage design invokes more attention and consumes self-control resources, as reflected by P2 and LPP. Generally, these findings imply that appropriately low-order designed webpages can give rise to increased instant purchase in online shopping. These findings will be beneficial for future E-commerce studies.

\section{Acknowledgments}

This work was supported by Grants No. 71602044, No. 71572176, No. 71603139 and No. 71502047 from the National Natural Science Foundation of China; Grant No.16ZJQN030YB of the Zhejiang Youth Social Science Fund; Grant No. LQ16G020006 from the Natural Science Foundation of Zhejiang Province of China; Grant No. 15NDJC031YB from the Philosophy and Social Science Planning Project of Zhejiang Province; and Grand No. AHSKQ2017D67 from the Philosophy and the Social Sciences Planned Project of Anhui Province.

\section{Disclosure}

The authors report no conflicts of interest in this work.

\section{References}

1. Rook DW. The buying impulse. J Consum Res. 1987;14(2):189-199. doi:10.1086/209105

2. Sultan AJ, Joireman J, Sprott DE. Building consumer self-control: the effect of self-control exercises on impulse buying urges. Mark Lett. 2012;23(1):61-72. doi:10.1007/s11002-011-9135-4

3. Youn S, Faber RJ. Impulse buying: its relation to personality traits and cues. ACR North Am Adv. 2000. http://acrwebsite.volumes/8383/ volumes/v27/NA-27.

4. Parsad C, Prashar S, Vijay TS, Kumar M. In-Store Stimuli and Impulsive Buying Behaviour: modeling Through Regression Equation. Int J Strategic Decis Sci. 2018;9(3):95-112. doi:10.4018/ ijsds2018070105

5. Adelaar T, Chang S, Lancendorfer KM, Lee B, Morimoto M. Effects of media formats on emotions and impulse buying intent. $J$ Inf Technol. 2003;18(4):247-266. doi:10.1080/0268396032000150799

6. Akram U, Hui P, Kaleem Khan M, Tanveer Y, Mehmood K, Ahmad W. How website quality affects online impulse buying: moderating effects of sales promotion and credit card use. Asia Pac J Mark Logist. 2018;30 (1):235-256. doi:10.1108/apjml-04-2017-0073

7. Lavie T, Tractinsky N. Assessing dimensions of perceived visual aesthetics of web sites. Int J Hum Comput Stud. 2004;60 (3):269-298. doi:10.1016/j.ijhcs.2003.09.002

8. Deng L, Poole MS. Affect in web interfaces: a study of the impacts of web page visual complexity and order. Mis Quarterly. 2010;711-730. doi: $10.2307 / 25750702$

9. Teng PS, Cai D Exploring Aesthetic Impression Of Web Pages From Aspects Of Visual Order And Complexity. Paper presented at: International Conference on Communication, Media, Technology and Design (ICCMTD)2012. doi:10.1094/PDIS-11-11-0999-PDN

10. Bandodkar N, Singh R The Impact of Webpage Visual Characteristics on Consumer's Initial Trust In E-Vendors. 2015. SAIS 2015 Proceedings. 22. Hilton Head Island, SC, USA. https://aisel.aisnet.sais2015/22.

11. Pengnate S, Sarathy R, Lee J. The engagement of website initial aesthetic impressions: an experimental investigation. Int J Hum Comput Interact. 2019;35(16):1517-1531. doi:10.1080/10447318.2018.1554319

12. Bitner MJ. Evaluating service encounters: the effects of physical surroundings and employee responses. J Mark. 1990;69-82. doi:10.2307/ 1251871

13. Tangsupwattana W, Liu X. Effect of emotional experience on symbolic consumption in Generation Y consumers. Mark Intell Plann. 2018;36(5):514-527. doi:10.1108/mip-11-2017-0316

14. Wu L, Li J, Lei T. Design Entropy: a New Approach for Evaluating User Experience in User Interface Design. In: Rebelo F, Soares M, editors. Advances in Ergonomics in Design. Vol. 4852016. Cham: Springer; 583-593. doi:10.1007/978-3-319-41983-1_53.

15. Kotabe HP. The world is random: a cognitive perspective on perceived disorder. Front Psychol. 2014;5:606. doi:10.3389/ fpsyg.2014.00606

16. Vohs KD, Faber RJ. Spent resources: self-regulatory resource availability affects impulse buying. J Consum Res. 2007;33(4):537-547. doi:10.1086/510228

17. Robinson MD, Schmeichel BJ, Inzlicht M. A cognitive control perspective of self-control strength and its depletion. Soc Personal Psychol Compass. 2010;4(3):189-200. doi:10.1111/j.1751-9004.2009.00244.x

18. Timpano KR, Schmidt NB. The Association Between Self-Control and Hoarding: a Case Report. Cogn Behav Pract. 2010;17 (4):439-448. doi:10.1016/j.cbpra.2009.06.006

19. Vohs K, Faber R. Self-regulation and impulsive spending patterns. $A C R$ North Am Adv. 2003. http://acrwebsite.volumes/8746/volumes/v30/NA30.

20. Gailliot MT, Baumeister RF, DeWall CN, et al. Self-control relies on glucose as a limited energy source: willpower is more than a metaphor. J Pers Soc Psychol. 2007;92(2):325-336. doi:10.1037/ 0022-3514.92.2.325 
21. Fenton-O'Creevy M, Dibb S, Furnham A. Antecedents and consequences of chronic impulsive buying: can impulsive buying be understood as dysfunctional self-regulation? Psychol Mark. 2018;35 (3): 175-188. doi:10.1002/mar.21078

22. Efendi R, Indartono S, Sukidjo S. The Mediation of Economic Literacy on the Effect of Self Control on Impulsive Buying Behaviour Moderated by Peers. Int J Econ Financial Issues. 2019;9 (3):98. doi:10.32479/ijefi.7738

23. Cerf M, Greenleaf E, Meyvis T, Morwitz VG. Using single-neuron recording in marketing: opportunities, challenges, and an application to fear enhancement in communications. J Mark Res. 2015;52 (4):530-545. doi:10.1509/jmr.13.0606

24. Luck SJ. An Introduction to the Event-Related Potential Technique. MIT press; 2005.

25. Ibanez A, Melloni M, Huepe D, et al. What event-related potentials (ERPs) bring to social neuroscience? Soc Neurosci. 2012;7 (6):632-649. doi:10.1080/17470919.2012.691078

26. Luck SJ, Woodman GF, Vogel EK. Event-related potential studies of attention. Trends Cogn Sci. 2000;4(11):432-440. doi:10.1016/S13646613(00)01545-X

27. Ma Q, Jin J, Wang L. The neural process of hazard perception and evaluation for warning signal words: evidence from event-related potentials. Neurosci Lett. 2010;483(3):206-210. doi:10.1016/j. neulet.2010.08.009

28. González-Villar AJ, Triñanes Y, Zurrón M, Carrillo-de-la-Peña MT. Brain processing of task-relevant and task-irrelevant emotional words: an ERP study. Cognit Affective Behav Neurosci. 2014;14 (3):939-950. doi:10.3758/s13415-013-0247-6

29. Carretié L, Mercado F, Tapia M, Hinojosa JA. Emotion, attention, and the 'negativity bias', studied through event-related potentials. Int J Psychophysiol. 2001;41(1):75-85. doi:10.1016/s0167-8760(00) 00195-1

30. Liu B, Xin S, Jin Z, Hu Y, Li Y. Emotional facilitation effect in the picture-word interference task: an ERP study. Brain Cogn. 2010;72 (2):289-299. doi:10.1016/j.bandc.2009.09.013

31. Wang X, Shangguan C, Lu J. Time course of emotion effects during emotion-label and emotion-laden word processing. Neurosci Lett. 2019;699:1-7. doi:10.1016/j.neulet.2019.01.028

32. Freunberger R, Klimesch W, Doppelmayr M, Höller Y. Visual P2 component is related to theta phase-locking. Neurosci Lett. 2007;426 (3):181-186. doi:10.1016/j.neulet.2007.08.062

33. Zioga I, Harrison PM, Pearce MT, Bhattacharya J, Luft CDB. From learning to creativity: identifying the behavioural and neural correlates of learning to predict human judgements of musical creativity. NeuroImage. 2019;116311. doi:10.1016/j.neuroimage.2019.116311

34. Lei Y, Li F, Long C, et al. How does typicality of category members affect the deductive reasoning? An ERP study. Exp Brain Res. 2010;204(1):47-56. doi:10.1007/s00221-010-2292-5

35. Ma Q, Wang C, Wang X. Two-stage categorization in brand extension evaluation: electrophysiological time course evidence. PLoS One. 2014;9(12):e114150. doi:10.1371/journal.pone.0114150

36. Moser JS, Hajcak G, Bukay E, Simons RF. Intentional modulation of emotional responding to unpleasant pictures: an ERP study. Psychophysiology. 2006;43(3):292-296. doi:10.1111/j.1469-8986.2006. 00402.x

37. Thiruchselvam R, Blechert J, Sheppes G, Rydstrom A, Gross JJ. The temporal dynamics of emotion regulation: an EEG study of distraction and reappraisal. Biol Psychol. 2011;87(1):84-92. doi:10.1016/j. biopsycho.2011.02.009
38. Huang Y-X, Luo Y-J. Temporal course of emotional negativity bias: an ERP study. Neurosci Lett. 2006;398(1):91-96. doi:10.1016/j. neulet.2005.12.074

39. Dennis TA, Hajcak G. The late positive potential: a neurophysiological marker for emotion regulation in children. J. Child Psychol. Psychiatry. 2009;50(11):1373-1383. doi:10.1111/j.1469-7610.2009.02168.x

40. Moser JS, Most SB, Simons RF. Increasing negative emotions by reappraisal enhances subsequent cognitive control: a combined behavioral and electrophysiological study. Cognit Affective Behav Neurosci. 2010;10(2):195-207. doi:10.3758/cabn.10.2.195

41. Brudner EG, Denkova E, Paczynski M, Jha AP. The role of expectations and habitual emotion regulation in emotional processing: an ERP investigation. Emotion. 2018;18(2):171. doi:10.1037/emo0000313

42. Dunning JP, Hajcak G. See no evil: directing visual attention within unpleasant images modulates the electrocortical response. Psychophysiology. 2009;46(1):28-33. doi:10.1111/j.1469-8986.2008. 00723.x

43. Wang X, Huang Y, Ma Q, Li N. Event-related potential P2 correlates of implicit aesthetic experience. Neuroreport. 2012;23(14):862-866. doi:10.1097/wnr.0b013e3283587161

44. Hansen B, Howe A, Sutton P, Ronan K. Impact of client feedback on clinical outcomes for young people using public mental health services: a pilot study. Psychiatry Res. 2015;229(1-2):617-619. doi:10.1016/j.psychres.2015.05.007

45. Ssewamala FM, Alicea S, Bannon WM Jr, Ismayilova L. A novel economic intervention to reduce HIV risks among school-going AIDS orphans in rural Uganda. $J$ Adolesc Health. 2008;42 (1):102-104. doi:10.1016/j.jadohealth.2007.08.011

46. Lovakov A, Agadullina E Empirically derived guidelines for interpreting effect size in social psychology. 2017. doi:10.31234/osf.io/2epc4

47. Takahashi KJ, Earl A. Effect of Extraneous Affect on Health Message Reception. Personality Soc Psychol Bull. 2020;46(2):270-284. doi: $10.1177 / 0146167219855042$

48. Vohs KD, Heatherton TF. Self-regulatory failure: a resource-depletion approach. Psychol Sci. 2000;11(3):249-254. doi:10.1111/1467-9280. 00250

49. Blanchet S, Gagnon G, Bastien C. Event-related potential study of dynamic neural mechanisms of semantic organizational strategies in verbal learning. Brain Res. 2007;1170:59-70. doi:10.1016/j.brainres. 2007.07.024

50. Shaw K, Lien M-C, Ruthruff E, Allen PA. Electrophysiological evidence of emotion perception without central attention. $J$ Cogn Psychol. 2011;23(6):695-708. doi:10.1080/20445911.2011.586624

51. Cohen N, Henik A, Moyal N. Executive control attenuates emotional effects-for high reappraisers only? Emotion. 2012;12(5):970. doi: $10.1037 / \mathrm{a} 0026890$

52. Shang Q, Huang Y, Ma Q. Hazard levels of warning signal words modulate the inhibition of return effect: evidence from the event-related potential P300. Exp Brain Res. 2015;233(9):2645-2653. doi:10.1007/ s00221-015-4335-4

53. Quan N, Chi N, Nhung D, Ngan N, Phong L. The influence of website brand equity, e-brand experience on e-loyalty: the mediating role of e-satisfaction. Manag Sci Lett. 2020;10(1):63-76. doi: $10.5267 /$ j.msl.2019.8.015

54. Hwang H-C. Playing with Music While Shopping Online: The Effects of Interactive Music on Consumer Engagement and Behavioral Intention. 2018. http://hdl.handle.net/2152/67955. Accessed January 3, 2020.

55. Bleichner MG, Lundbeck M, Selisky M, et al. Exploring miniaturized EEG electrodes for brain-computer interfaces. An EEG you do not see? Physiol Rep. 2015;3(4). doi:10.14814/phy2.12362 


\section{Publish your work in this journal}

Psychology Research and Behavior Management is an international, peer-reviewed, open access journal focusing on the science of psychology and its application in behavior management to develop improved outcomes in the clinical, educational, sports and business arenas. Specific topics covered in the journal include: Neuroscience, memory and decision making; Behavior modification and management; Clinical applications; Business and sports performance management; Social and developmental studies; Animal studies. The manuscript management system is completely online and includes a very quick and fair peer-review system, which is all easy to use. Visit http://www. dovepress.com/testimonials.php to read real quotes from published authors.

Submit your manuscript here: https://www.dovepress.com/psychology-research-and-behavior-management-journal 